\title{
Real-time Implementation of Space Vector Modulation using Arduino as a Low-cost Microcontroller for Three-phase Grid- connected Inverter
}

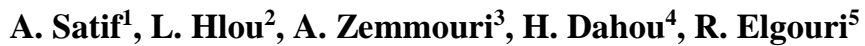 \\ ${ }^{1,5}$ Laboratory of Electrical Engineering and Telecommunications Systems, \\ National School of Applied Sciences, Kenitra, Morocco \\ 2,3,4 Laboratory of Electrical Engineering \& Energy Systems, \\ Faculty of Science Ibn Tofail University, Kenitra, Morocco
}

\begin{abstract}
Article Info
Article history:

ABSTRACT

Received Apr 7, 2019

Revised Mar 12, 2020

Accepted Mar 24, 2020

Keywords:

SVPWM

Synchronization

Three-phase inverter

This work aims to facilitate the approach of a promising and fascinating technology, which is the photovoltaic (PV) energy, concerning the integration of PV systems to the utility grid from the control/synchronization point of view. Within this context, this paper gives a performance analysis of modeling and driving a two-level three-phase inverter, in order to reduce the variations in frequency and phase, as a result, the synchronization between the inverter and the utility grid is accomplished and the correct function of the inverter is performed. MATLAB/Simulink software was utilized to develop the model of the suggested control algorithms. Then, as an interfacing device between the software and the inverter, the Arduino UNO microcontroller is proposed as a low-cost and simplified method to control the three-phase inverter.
\end{abstract}

Arduino UNO

Copyright $@ 2019$ Institute of Advanced Engineering and Science. All rights reserved.

\section{Corresponding Author:}

A. Satif,

Laboratory of Electrical Engineering and Telecommunications Systems,

National School of Applied Sciences, Kenitra, Morocco.

Email: amal.satif@uit.ac.ma

\section{INTRODUCTION}

All Distributed generation systems based on renewable energy resources (RES) such as wind and solar are now popular choices to reduce the world's dependence on fossil-based fuels, which could deplete sooner or later [1]. As [2] has published, approximately $80 \%$ of energy production still depending on fossil fuels, which causes, as a result, global warming [3]. Therefore, the use of RES must be a priority because, as presented in [4], up until today only $15-20 \%$ of energy comes from RES even if they are durable and available in large quantities. However, numerous issues and specialized challenges should be considered for an efficient and successful association of RES into the utility grid. The most important and principal issues are the control of the three-phase grid-connected inverter to convert the DC electric energy from the RES generator into AC electric energy source, as well as the synchronization of the grid-side inverter, where the output voltage waveform should be synchronized with the grid voltage to guarantee a steady performance of the PV system [5], [6].

The three-phase grid-connected inverter should be able to transfer effectively the maximum quantity of the PV energy coming from the RES generator to the utility grid. So as to ensure a successful transformation, the inverter output current should be transmitted in phase and frequency with the voltage of the power utility grid. However, it is not simple to provide a sinusoidal current at the output of the inverter due to its complexity of circuit construction. Accordingly, to reply to the quality of power supply by which distributed generation systems are connected to the utility grid, various control techniques were suggested recently. As we all know, the major problem in the power converters is the reduction in harmonics, Pulse 
Width Modulation (PWM) techniques offer the most suitable solution for harmonics reduction. These techniques are classified into two major categories, namely: triangular comparison-based PWM and space vector-based PWM. In the triangular comparison-based PWM, PWM waves are produced by the combination of a triangular carrier, with a relatively high frequency, and a fundamental modulating reference signal. PWM and synchronous PWM (SPWM) are the core techniques to be mentioned in triangular comparisonbased PWM [7]. In SVPWM, the revolving reference vectors provide the reference signals, this technique is considered as the more advanced one for PWM generation for getting a qualified sinusoidal output with low total harmonic distortion (THD) and small current ripples [7]-[9].

The synchronization method can be defined as the minimization of the changes in frequency, voltage, and phase angle between the RES generator output and the utility grid. Such synchronization must be done before the connection of the RES generator with the power grid [10], [11]. So that the synchronized power inverter and the power grid could work together [12]. Given a large number of problems concerning grid interconnection and to ensure the synchronization of the grid-connected inverters, several methods for phase and frequency estimation have been proposed in the last few decades [5], some commonly used techniques found in credible research articles are zero-crossing technique, filtering of grid voltages, and phase locked loop technique, a detailed description of each mentioned technique is given in [13]. The PLL technique is found as the most suitable for rejecting notches, grid harmonics, and other disturbances [13].

The different characteristics of the methods presented above show the reason for the choice of the synchronization technique and the modulation scheme to be used in this work.

There are several electronic devices that can be used as an intermediate between Simulink and project setups, among them, we cite DSP (Digital Signal Processor), dSPACE (Digital Signal Processing and Control Engineering), FPGA (Field Programmable Gate Arrays), and Raspberry. However, these devices have their drawbacks and limitations, namely: the expensive cost, moderate processing, complex implementations, and higher switching losses. To overcome these limitations, the Arduino UNO microcontroller was chosen. The advantages of using this board are low-cost, simplicity and clear programming environment [14].

\section{METHODOLOGY}

In this paper, we used a proven space vector PWM as the power technique to drive three-phase gridconnected inverters. First, the software of MathWorks was used to design and develop the method in order to validate its performance. Then, to connect the three-phase inverter with the software, the Arduino UNO microcontroller is used. The switching signals generated from Simulink software are uploaded into the microcontroller. MATLAB/Simulink software was used to create and design the model of the SVPWM algorithm and the phase-locked loop structure (PLL) to guarantee the current synchronization between the utility grid and the inverter. The output waveforms at the Arduino output were visualized using a digital oscilloscope, as well as the phase-to-phase voltages at the output of the three-phase inverter. This work was able to generate SVPWM switching signals using a simple and non-expensive interfacing platform, which is the Arduino board. Therefore, the interfacing between the software and the hardware becomes simple without using any programming code to generate SVPWM into the three-phase inverter.

\section{GRID-CONNECTED PHOTOVOLTAIC SYSTEM}

The fundamental function of PV grid-connected systems is to drive the power flow between the RES and the utility power grid [15], as well as the power factor of the grid-connected inverter [16]. The power conditioner must ensure the maximum efficiency by delivering the maximum incoming power from the PV module into the power utility grid. We can classify PV grid-connected systems into two subsystems [16], the power and the control subsystem, whose block diagrams are given in Figure 1.

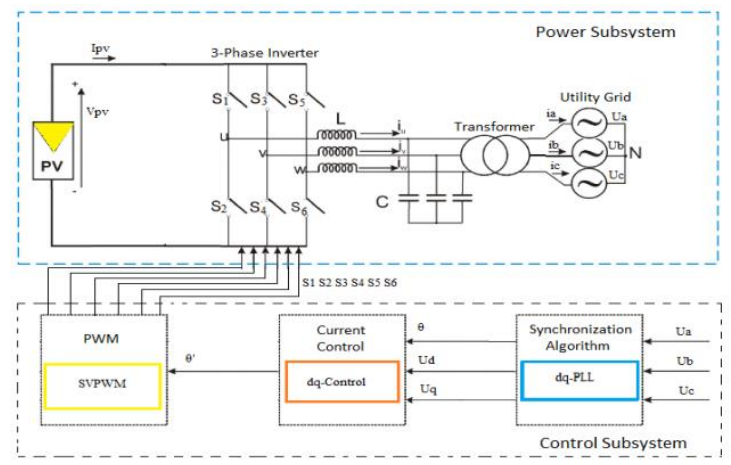

Figure 1. The power and control subsystems for the grid-connected PV system 


\subsection{Power subsystem}

The fundamental elements of the power subsystem are the PV modules, the two-level three-phase inverter, and the LC filter. Next, a short depiction of each unit is discussed.

\subsubsection{Photovoltaic modules}

PV modules can be considered as an essential component of grid-connected PV systems. As depicted in [17], several types of PV modules technologies exist, and they differ in the levels of productivities. Providing the desired power for the renewable grid-connected system presents the main objective of PV modules, depending on the quantities of solar irradiance and temperature [18]. It should be mentioned that there is a related dependence between the size of the PV module and the required power of the PV system.

\subsubsection{Two-level three-phase inverter}

As shown in Figure 2, the two-level three-phase inverter, principally constructed with semiconductor electronic devices [19] (IGBTs or MOSFETs), can be considered as the brain of a PV system, its main role is the transformation of the generated DC voltage into suitable AC currents to be generated to the three-phase low-voltage utility grid. as mentioned previously, Pulse width modulation (PWM) and space vector modulation (SVM) techniques are applied as power control methods to drive power switches of the inverter [20] depending on the average voltage and current references.

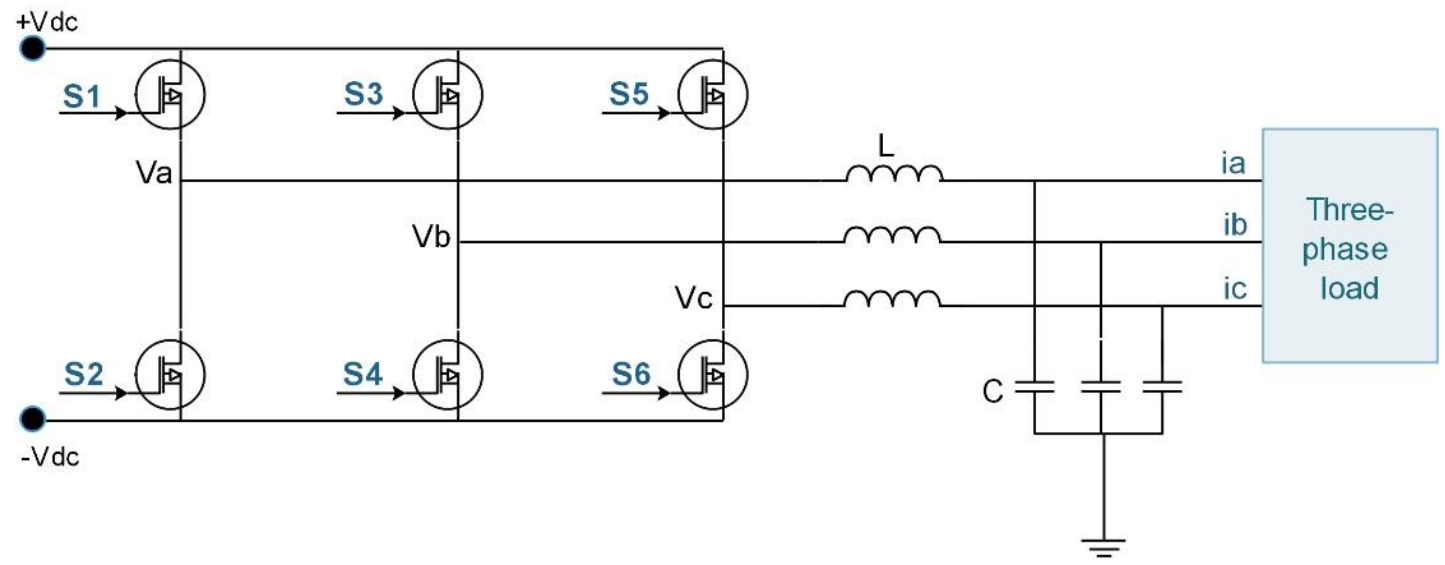

Figure 2. Two-level three-phase inverter configuration

\subsubsection{LC filter}

Renewable agents must perform the power quality regulations, in addition to ensuring a constant power delivery to the three-phase power utility grid. As indicated by several research works [21], the maximum total harmonic distortion (THD) for the three-phase currents must be around 5\%. A resume of different norms about power quality for PV systems can be obtained in [22]. The non-linear load is the principal cause of the low order harmonics when the ripples in the inverter output currents are caused by the high-frequency commutation of the IGBTs. The use of the LC filter on the inverter-grid side is the optimal solution to reduce the high-frequency ripples [23].

\subsection{Control subsystem}

\subsubsection{Synchronization algorithm}

The synchronization algorithm must detect the phase angle of the three-phase utility grid voltages with good precision and dynamic response in order to guarantee the synchronization of the controlled threephase inverter currents and guarantee the correct behavior of the inverter control method. Different synchronization structures are given by several studies [5], [24]. Consequently, due to its advantages, the Phase-Locked Loop (PLL) can be considered as the optimal one. Figure 3 illustrates the three-phase PLL structure, which is performed by Park (abc-dq) transformation, a PI regulator [23] with the role of the loop filter, and an integrator as the Voltage Controlled Oscillator (VCO). 


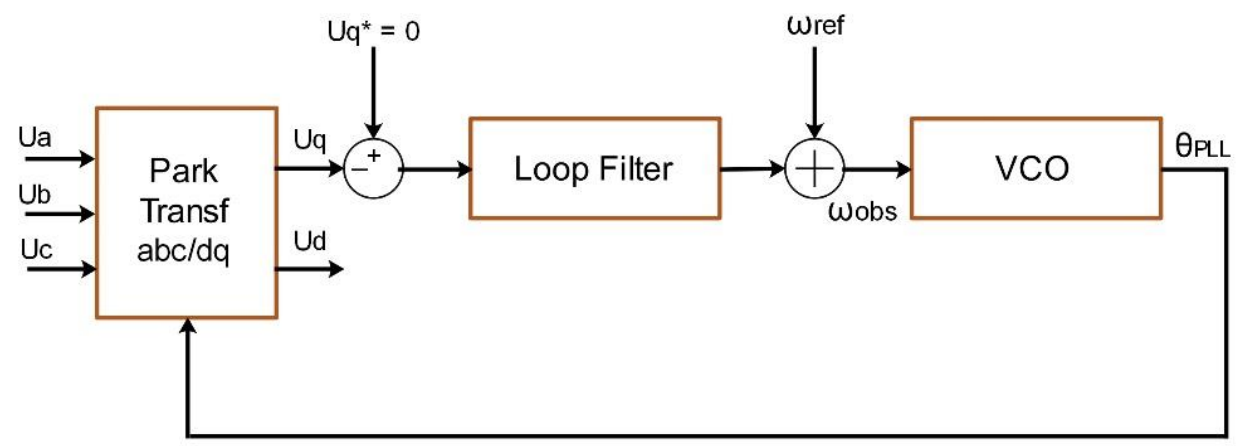

Figure 3. Block diagram of the dq-PLL synchronization structure

This synchronization algorithm is also named the Synchronous Reference Frame PLL (SRF-PLL) or dqPLL: its input variables are the three-phase voltages of the grid ( $\mathrm{Ua}, \mathrm{Ub}, \mathrm{Uc}$ ). As presented in Figure 3, the grid frequency is generated at the output of the loop filter. Then, a Voltage Controlled Oscillator (VCO) is connected, this is, in our case, an integrator which gives the phase locked angle $(\theta)$ of the grid as the output variable of the dqPLL.

\subsubsection{Current control}

The implemented control technique has been performed using a current regulation, based on PI controllers [15]: the current control loop uses two controllers to regulate the $d-q$ components of the line currents in order to ensure the synchronization of the three-phase inverter line currents with the three-phase utility grid voltages. A block diagram of the current control equivalent model for PV three-phase inverters is described in Figure 4.

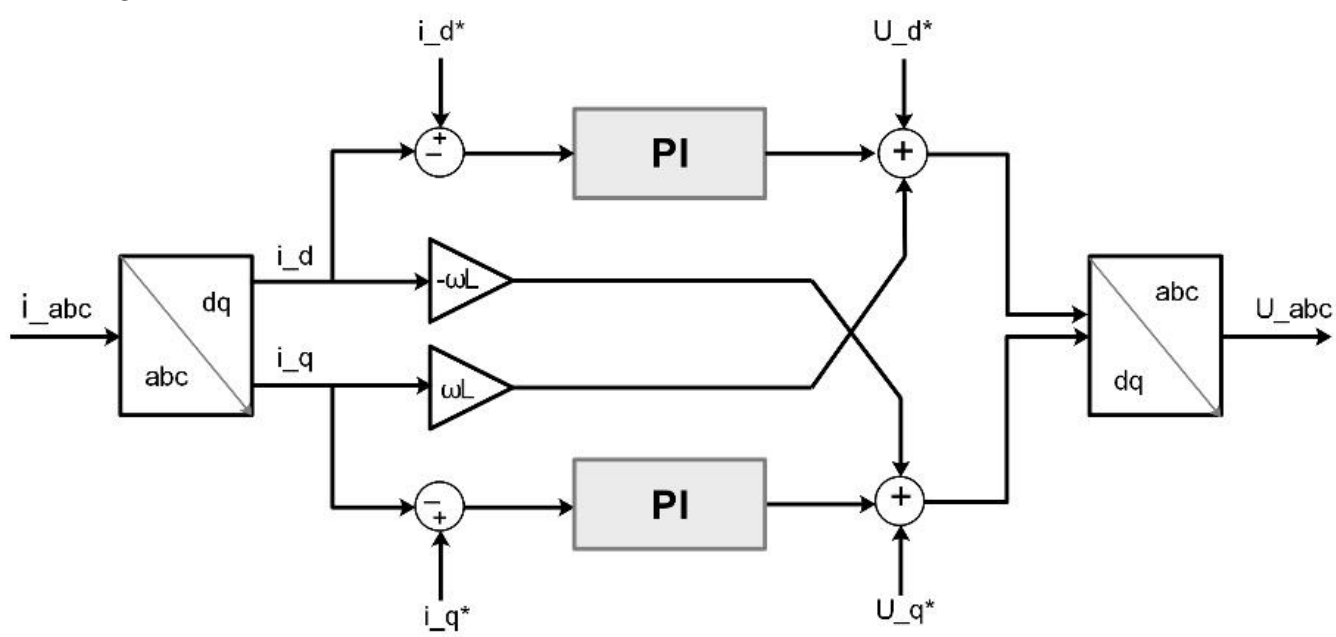

Figure 4. Block diagram of the PI current control method

\subsubsection{SVPWM}

After calculating the reference three-phase currents using the current control structure, the Pulse Width Modulation (PWM) strategy is used to produce the gating pulses to be generated to the individual inverter switches, in order to guarantee the desired three-phase inverter voltage [21]. Numerous PWM methods have been depicted and developed in the last few decades. However, with microprocessor evolution, the space vector modulation (SVM) becomes prominent and possibly the perfect PWM technique for the three-phase inverter. The constant switching frequency and excellent DC-link voltage utilization can be considered as the principal point of interest for the SVM.

For a three-phase two-level inverter, as shown in Figure 5, there are eight possible different states, each of them determines a voltage space vector. Figure 6 shows that the six voltage space vectors form the axis of a hexagon and divide the space into six sectors from 1 to 6 . Between each two adjacent non-zero vectors an angle of $60^{\circ}$. Therefore, the objective of space vector modulation digital modulating technique is to approximate a given reference voltage determining a combination of active and zero vectors [25]. 

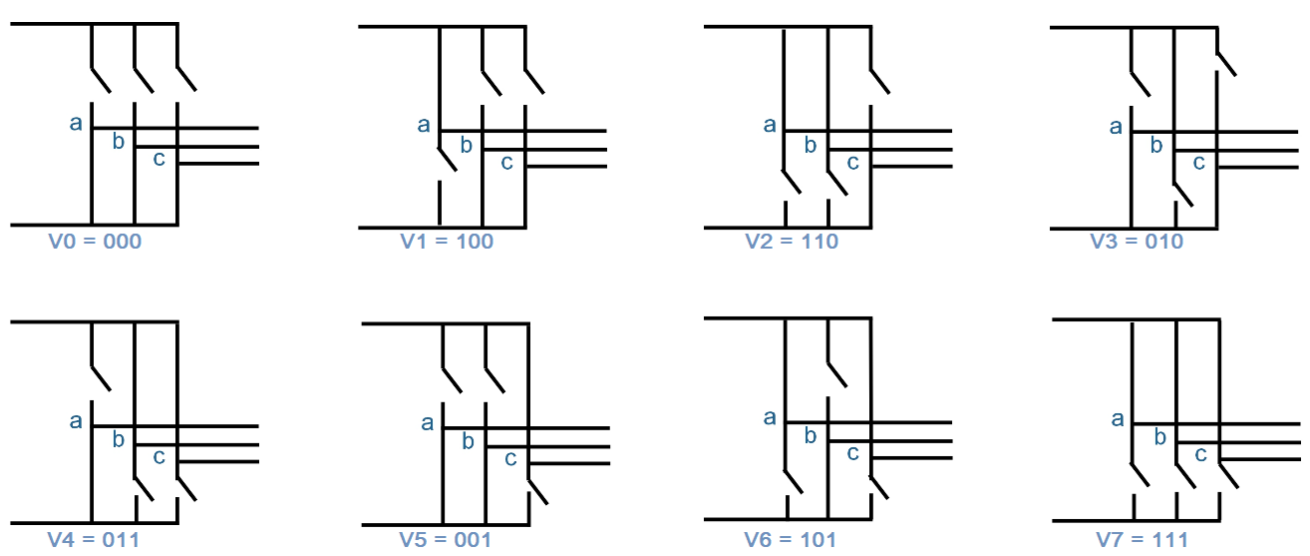

Figure 5. Eight switching configurations

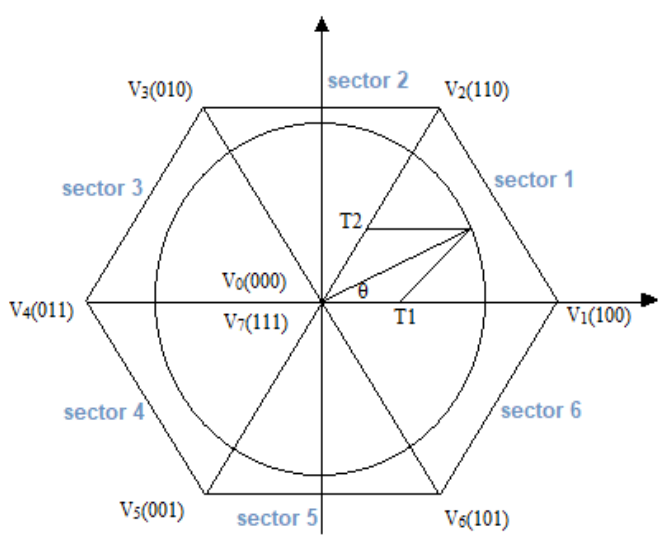

Figure 6. Space vectors in SVM

In SVM, the three-phase reference voltages $\mathrm{U}_{\mathrm{a}} *, \mathrm{U}_{\mathrm{b}} *$, and $\mathrm{U}_{\mathrm{c}} *$ are converted to the complex twophase orthogonal $(\alpha \beta)$ plane. This is known as Clarke's transformation, which can be computed by equation (1).

$$
\left[\begin{array}{l}
\mathrm{U}_{\alpha} \\
\mathrm{U}_{\beta}
\end{array}\right]=\left[\begin{array}{rrr}
1 & -\frac{1}{2} & -\frac{1}{2} \\
0 & \frac{\sqrt{3}}{2} & -\frac{\sqrt{3}}{2}
\end{array}\right]\left[\begin{array}{l}
\mathrm{U}_{\mathrm{a}}^{*} \\
\mathrm{U}_{\mathrm{b}}^{*} \\
\mathrm{U}_{\mathrm{c}}^{*}
\end{array}\right]
$$

Space Vector Modulation can be effected through the following steps [10]:

a. Calculation of the reference voltage and angle ( $\left.\theta^{\prime}\right)$, and can be calculated as follows in equation (2) and (3).

$$
\begin{aligned}
& U_{\text {ref }}=\sqrt{U_{\alpha}^{2}+U_{\beta}^{2}} \\
& \theta^{\prime}=\tan ^{-1} \frac{U_{\beta}}{U_{\alpha}}
\end{aligned}
$$

b. Identification of sector number that is calculated by comparing the angle determined from the last step with angles range of each sector.

c. Calculation of time duration $\mathrm{T} 1, \mathrm{~T} 2$, and $\mathrm{T} 0$ for each sector, that can be determined by the following equations: (4), (5), (6) and (7):

$$
\begin{aligned}
\mathrm{m} & =\frac{\mathrm{U}_{\mathrm{ref}}}{\mathrm{U}_{\mathrm{dc}} / 2} \\
\mathrm{~T} 1 & =\sqrt{\frac{3}{2}} \mathrm{~T}_{\mathrm{s}} \mathrm{m} \sin \left(\frac{\pi}{3}-\theta^{\prime}\right) \\
\mathrm{T} 2 & =\sqrt{\frac{3}{2}} \mathrm{~T}_{\mathrm{s}} \mathrm{m} \sin \left(\theta^{\prime}\right) \\
\mathrm{T} 0 & =\mathrm{T}_{\mathrm{s}}-\mathrm{T} 1-\mathrm{T} 2
\end{aligned}
$$


Where Uref is the amplitude of the desired output fundamental component, $\mathrm{T}_{\mathrm{s}}$ is the sampling period, Udc is the dc-bus voltage, and $\theta^{\prime}$ is the phase angle of the grid voltage. When time durations (T1, T2, and T0) are calculated for each sector, the SVM pulses are computed and then generated to the three-phase inverter. The arrangement of the switching sequence must guarantee the minimum transition between every two adjacent vectors. This method reduces the switching frequency and has less harmonics [26].

\section{THREE-PHASE GRID-CONNECTED INVERTER DESIGN}

The grid-connected inverter system modeled in Figure 1 consists of two fundamental sections: the software system (the program of the microcontroller) and the control system (practical system).

\subsection{Software System}

In this part, the proposed system is modeled in view of the theoretical basics presented previously in section 3. The system is then simulated to confirm the effectiveness of its parameters by using MATLAB/Simulink. The three-phase inverter input is $400 \mathrm{~V} \mathrm{DC}$. The association of an inverter to the utility grid is regularly done by the utilization of a grid filter whose objective is to attenuate harmonics in the inverter output voltage.

In the simulation model, $1.1 \mathrm{mH}$ inductors with an $0.045-\mathrm{Ohm}$ internal resistance and $4 \mathrm{uF}$ capacitors are used as an LC-filter in order to attain the desired voltage and reduce ripples in current characteristics. Then, a three-phase step-up transformer is used to realize isolation, DC decoupling and step-up voltage to $220 \mathrm{~V}$ phase-to-neutral for grid connection. To measure the injected current into the grid and the grid voltage, three current sensors and three voltage sensors are used respectively. Finally, a three-phase $220 \mathrm{~V}, 50 \mathrm{~Hz}$ AC source is used to model the utility grid.

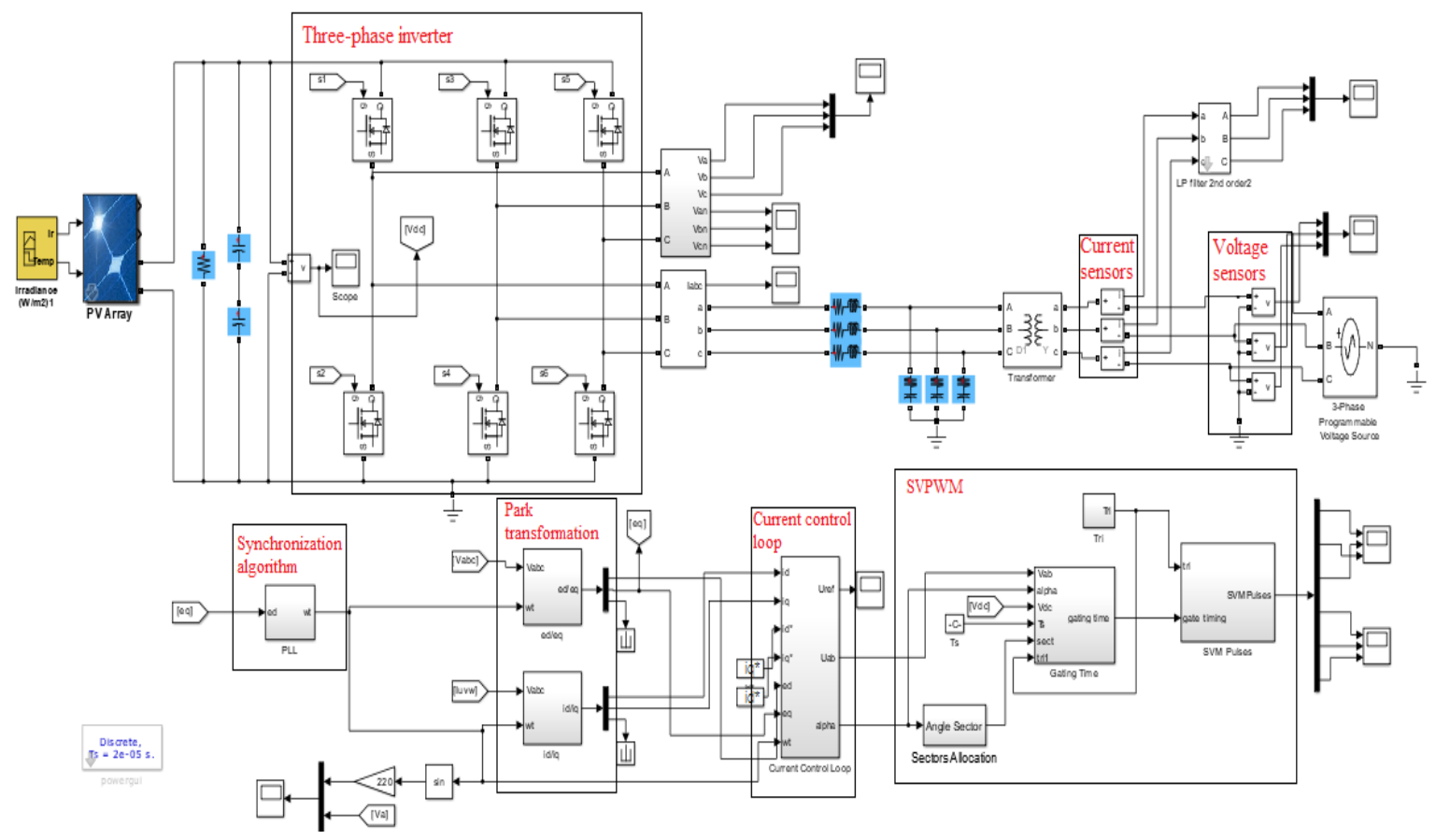

Figure 7. Grid-connected photovoltaic system simulation

Figure 7 shows the Simulink model of the proposed PV system, where a discrete model is used with a sample time of $0.2 \mu \mathrm{s}$. The model is composed of the power and control subsystems determined previously. Figure 8 (a) and 8 (b) present, successively, the simulation results of the phase angle and the synchronization between the grid voltage and the PLL output voltage. Figure 9 (a) and 9 (b) give, respectively, the time evolution of simple voltages and currents at the output of the three-phase inverter. Figure 10 gives the pulses for the inverter three upper switches (S1, S3, and S5). 


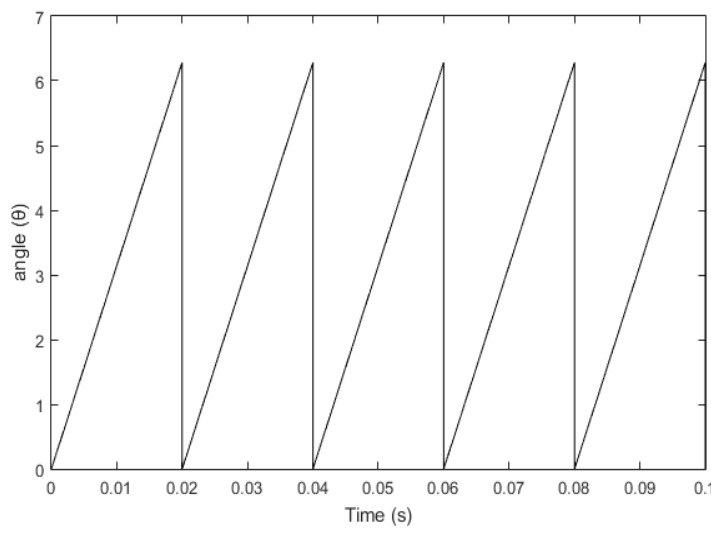

(a)

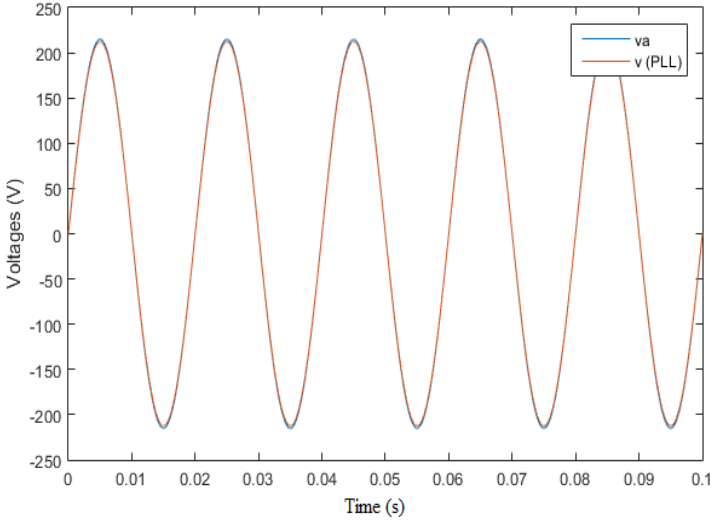

(b)

Figure 8. (a) Time evolution of the detected phase angle ( $\theta$ ). (b) Grid voltage and voltage at the PLL output

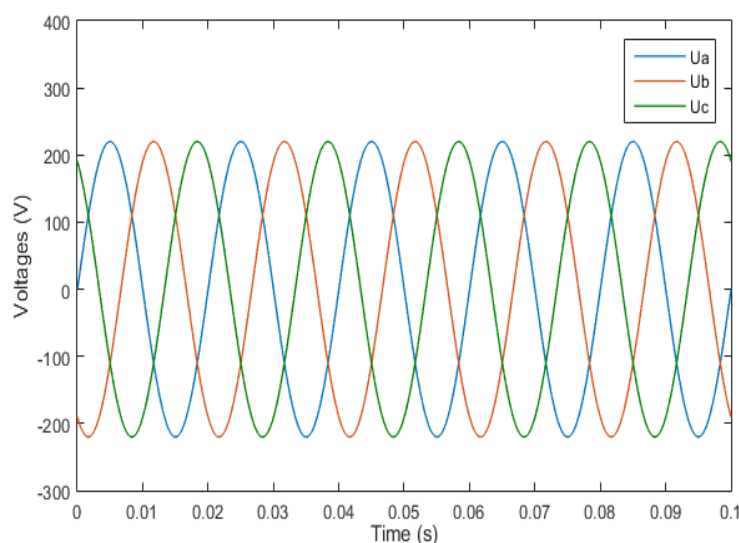

(a)

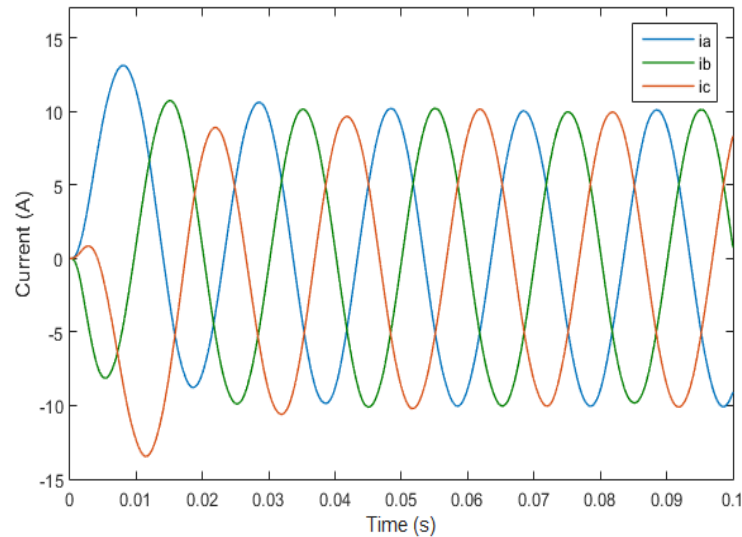

(b)

Figure 9. (a) Inverter three-phase line output voltages. (b) Currents waveforms injected to the utility grid

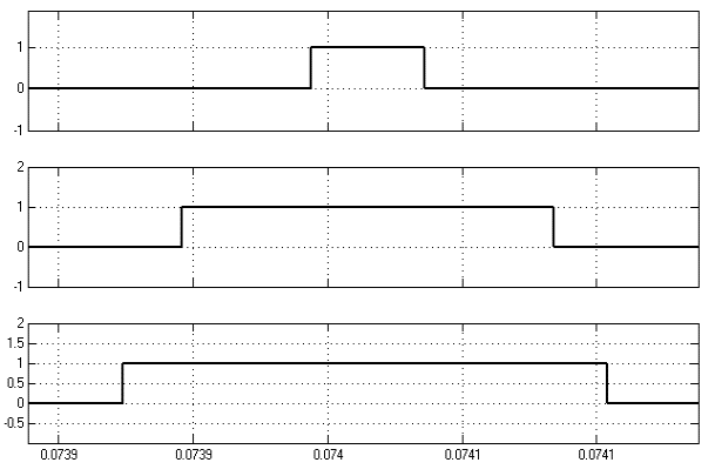

Figure 10. Output pulses for S1, S3, and S5

The simulation results described above of the overall grid-connected three-phase inverter prove that the six SVM gating signals $(\mathrm{S} 1, \mathrm{~S} 2, \ldots, \mathrm{S} 6)$ are generated to the power circuit, and the synchronization is done with success. At this point, the photovoltaic grid-connected system is managed successfully.

\subsection{Hardware System}

As determined before, the PV system was modeled and simulated in MATLAB/ Simulink software in order to verify its effectiveness. The transformation of the three-phase currents and voltages $\left(\mathrm{v}_{\mathrm{abc}} \mathrm{i}_{\mathrm{abc}}\right)$ into the two-phase referential $\left(\mathrm{V}_{\mathrm{dq}}, \mathrm{I}_{\mathrm{dq}}\right)$ is done, then the synchronization structure is designed to detect the phase angle used next to develop the mathematical model for the SVPWM and generate the inverter pulses. At this point, the Arduino UNO microcontroller functions as an interfacing component between software and hardware parts. Figure 10 shows the simulation setup for interfacing Simulink with Arduino UNO. Arduino 
pins from 3 to 11 are the selected digital output pins to generate the waveforms. We chose these pins due to their ability to generate the PWM output signals. It should be mensioned that in order to ensure a dead time between each two complementary switching signals, a delay time of $5 \mu$ s was introduced in the proposed model.

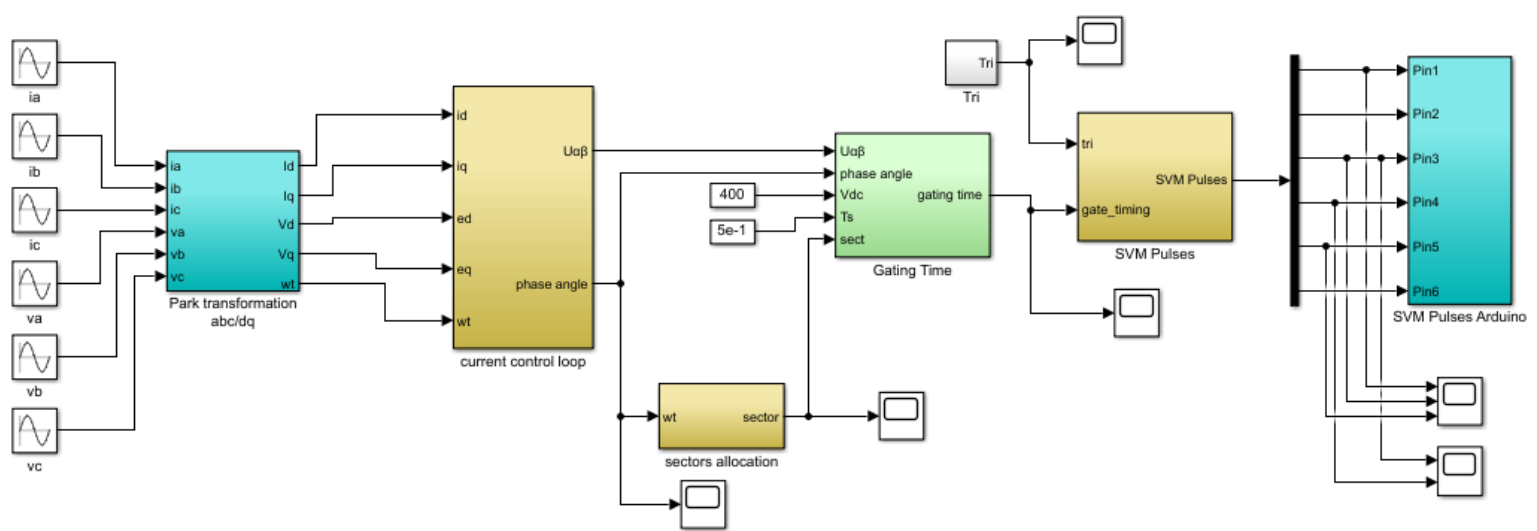

Figure 10. Simulation model of SVPWM and Interfacing between Simulink and Arduino UNO

The Arduino UNO is a single board microprocessor based on ATmega328P microcontroller that can be used in intelligent projects and prototyping. Controlling, sensing, and computing are the applications that can be executed by the Arduino microcontroller. Arduino UNO board contains 14 digital input and output pins (6 of them can be used as PWM outputs) and 6 analog inputs. Its operating voltage is 5V [27].

As presented above, the switching signals used for controlling the three-phase inverter are generated using MATLAB/Simulink, then the designed program is implemented on the microcontroller. The signals from the Arduino pins present the outputs of the SVPWM that functioned as switches signals for the inverter. Figure 11 exemplified the real-time hardware setup of our project.

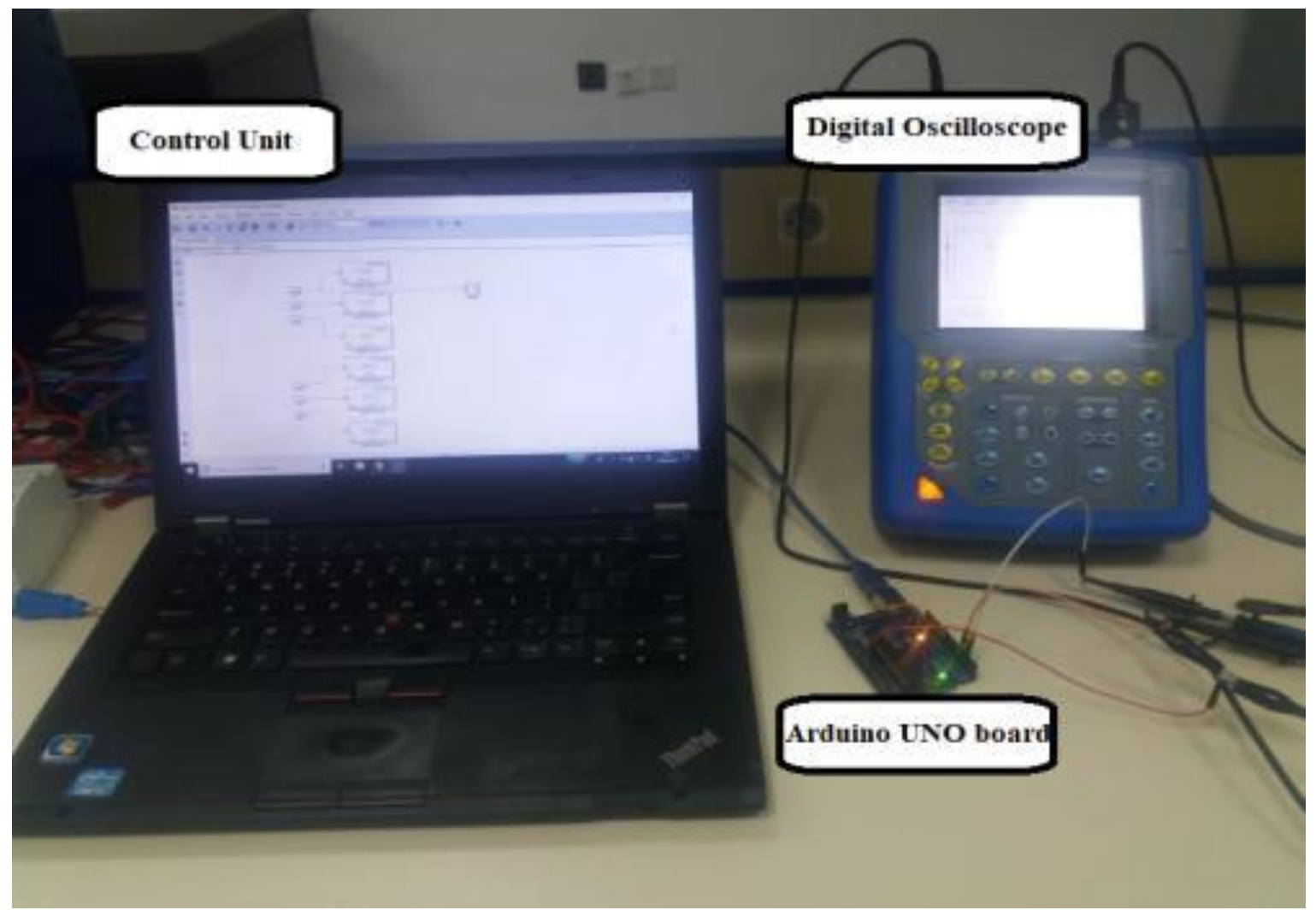

Figure 11. Hardware setup for Arduino microcontroller 


\section{RESULTS AND DISCUSSIONS}

The switching signals from the designed power control in MATLAB/ Simulink were uploaded and implemented in real-time to the Arduino board as presented previously in Figure 11. The SVPWM has 6 outputs (S1, S2, S3, S4, S5, and S6) which represent the six sectors, Figures 12 (a) and 12 (b) illustrate the real-time waveforms of the Arduino outputs using a digital oscilloscope.

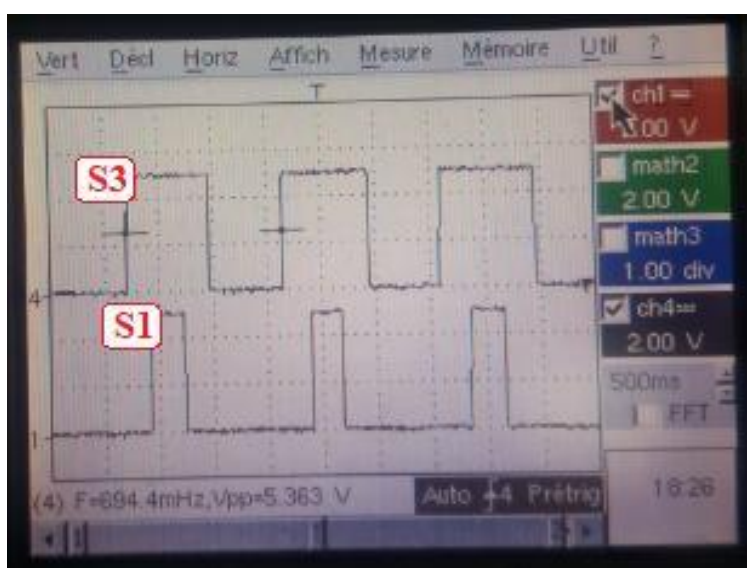

(a)

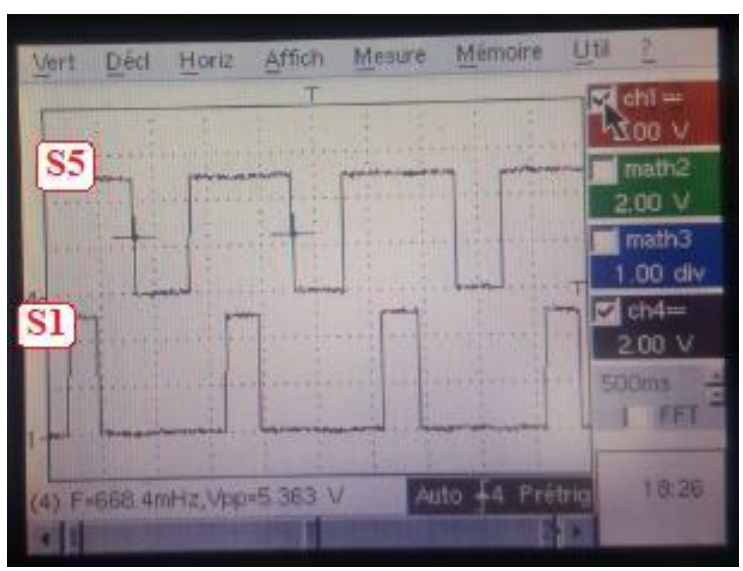

(b)

Figure 12. Output pulses from Arduino board. (a) S1 and S3, and (b) S1 and S5

Figure 13 (a) and 13 (b) show that the switching signals of one leg of the inverter are complementary with an introduced dead time of $5 \mu$ s as chosen in the simulation, which proves the validation of the designed model.

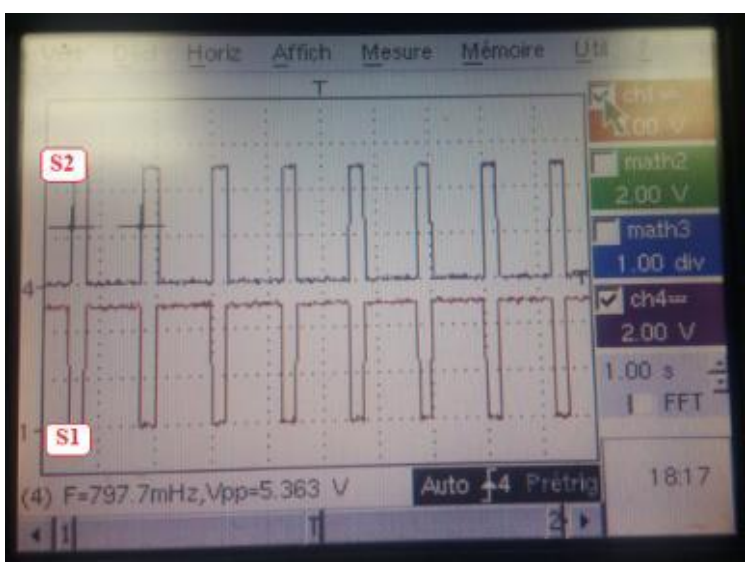

(a)

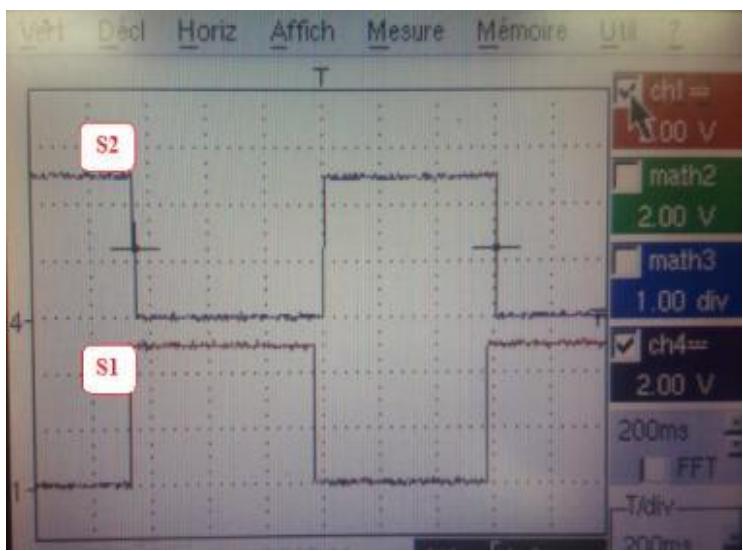

(b)

Figure 13. (a) Switching outputs of S1 and S2. (b) Dead time of $5 \mu$ s added to the switching signals

The prototype of the three-phase bridge inverter is set up in the laboratory and the three-voltages at the output of the inverter are measured using a digital oscilloscope, as shown respectively in Figure 14 and Figure 15. The gate pulses for controlling the inverter are generated using the Arduino board. Figure 14 shows the whole experimental setup. It contains four sections:

- Arduino microcontroller board, which generates the control signals of the three-phase inverter, in our prototype, we used the three upper control signals of the inverter legs (S1, S3, and S5);

- Isolation section, using an optocoupler PC817, which has two purposes: the isolation between power and control circuits and the amplification of the signals coming from Arduino UNO board from 5V to $15 \mathrm{~V}$;

- Driver section, using IR2111 driver in order to drive MOSFETs, one driver for each leg of the inverter is used;

- Inverter section, which consists of a two-level three-phase inverter, using IRF840 MOSFETs. 


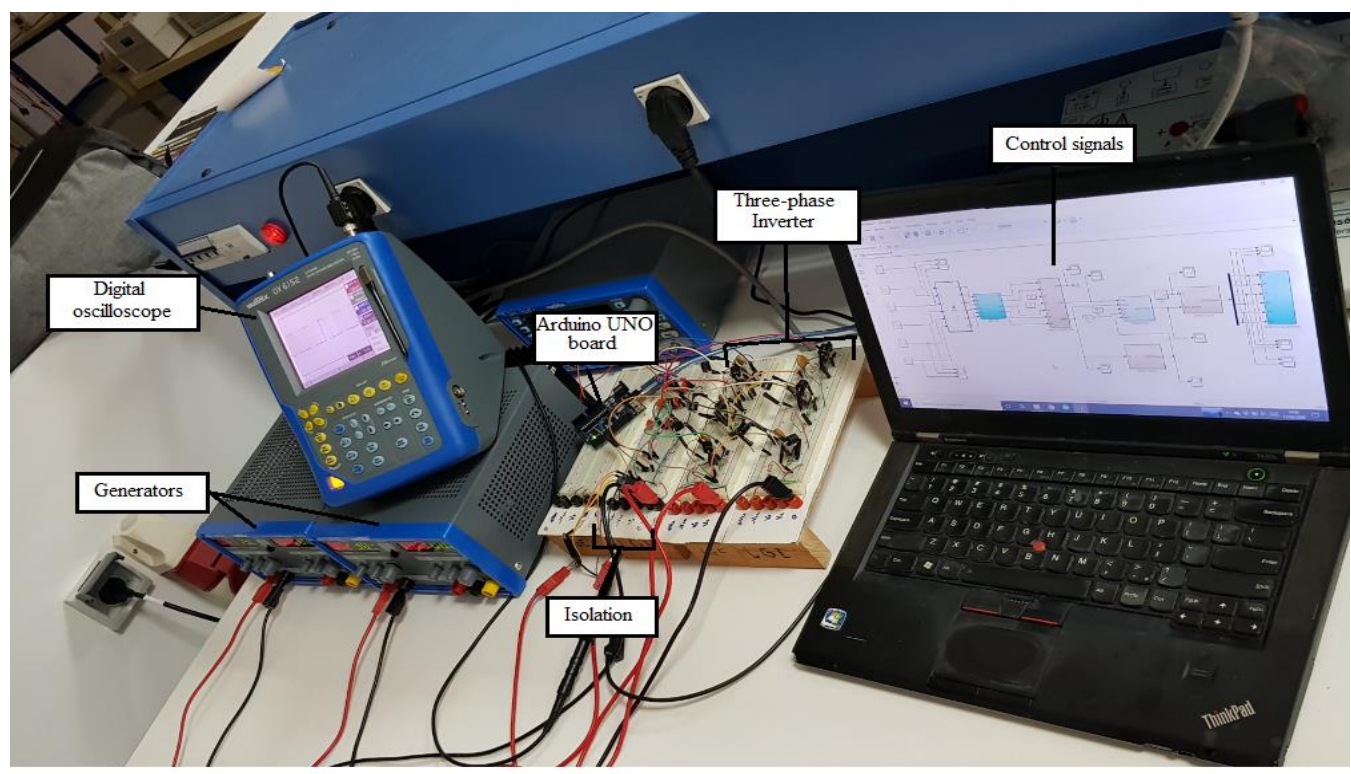

Figure 13. The entire experimental setup
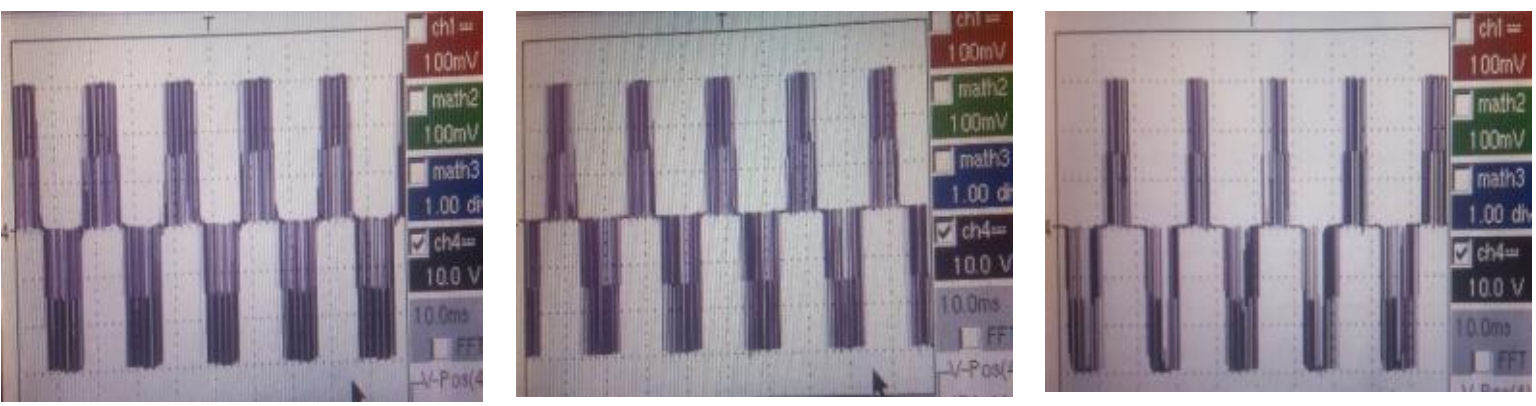

Figure 14. Three phase-to-phase voltages at the output of the inverter

From the simulation developed previously, as well as the hardware results, we can observe that the effectiveness of the proposed circuit is noteworthy. They clearly demonstrate that the simplified implementation of SVPWM is feasible and effectual in driving three-phase two-level inverters.

\section{CONCLUSION}

The problem of integrating photovoltaic modules into the building is different now from a few years ago when photovoltaic systems were only imagined in isolated sites. Photovoltaic comes to the city, by the technique of connection to the utility grid. Our principal objective in this work was to develop a simple and proven method to drive the three-phase inverter and reach the synchronization between the inverter and the electrical grid. A MATLAB simulation of the overall three-phase grid-connected system is presented to validate the effectiveness of the project parameters. Then, the Arduino UNO board was used as an intermediate between MATLAB/Simulink and the inverter presenting a low-cost, simple, and effective solution to generate waveform signals to drive the two-livel three-phase inverter. Therefore, considering the prominent results, this technique will help the beginner or student to use low-cost microcontrollers for electrical applications, namely: AC motor control and power converter driving.

\section{REFERENCES}

[1] H. Kizilaslan, "Input-output energy analysis of cherries production in Tokat Province of Turkey," Applied Energy, vol. 86, no. 7, pp. 1354-1358, Jul. 2009.

[2] F. Azadian and M. A. M. Radzi, "A general approach toward building integrated photovoltaic systems and its implementation barriers: A review," Renewable and Sustainable Energy Reviews, vol. 22, pp. 527-538, Jun. 2013.

[3] M. Hosenuzzaman, N. A. Rahim, J. Selvaraj, M. Hasanuzzaman, A. B. M. A. Malek, and A. Nahar, "Global prospects, progress, policies, and environmental impact of solar photovoltaic power generation," Renewable and Sustainable Energy Reviews, vol. 41, pp. 284-297, Jan. 2015. 
[4] J. O. Petinrin and M. Shaaban, "Renewable energy for continuous energy sustainability in Malaysia," Renewable and Sustainable Energy Reviews, vol. 50, pp. 967-981, Oct. 2015.

[5] N. Jaalam, N. A. Rahim, A. H. A. Bakar, C. Tan, and A. M. A. Haidar, "A comprehensive review of synchronization methods for grid-connected converters of renewable energy source," Renewable and Sustainable Energy Reviews, vol. 59, pp. 1471-1481, Jun. 2016.

[6] Y.-N. Tong, C.-L. Li, and F. Zhou, "Synchronization control of single-phase full bridge photovoltaic gridconnected inverter," Optik, vol. 127, no. 4, pp. 1724-1728, Feb. 2016.

[7] K. V. Kumar, P. A. Michael, J. P. John, and D. S. S. Kumar, "Simulation and comparison of SPWM and SVPWM control for three phase inverter," ARPN journal of engineering and applied sciences, vol. 5, no. 7, p. 15, 2010.

[8] D. Kalyanraj, M. Vignesh, N. S. Anwar, and S. S. Aravindan, "Performance Analysis of Different Current Control strategies for Grid Tied Three Phase Voltage Source Inverter," Journal of Control and Instrumentation Engineering, vol. 3, no. 1, pp. 19-27, Feb. 2017.

[9] L. Ibarra, P. Ponce, and A. Molina, "Generalized d-q frame PWM strategy for three-phase electric machineryÕ," IFAC-PapersOnLine, vol. 48, no. 3, pp. 1-7, Jan. 2015.

[10] R. Teodorescu, M. Liserre, and P. Rodriguez, Grid Converters for Photovoltaic and Wind Power Systems. John Wiley \& Sons, 2011.

[11] and and, "An improved space-vector-based hysteresis current controller," IEEE Transactions on Industrial Electronics, vol. 45, no. 5, pp. 752-760, Oct. 1998.

[12] A. Anzalchi and A. Sarwat, "Overview of technical specifications for grid-connected photovoltaic systems," Energy Conversion and Management, vol. 152, pp. 312-327, Nov. 2017.

[13] M. Parvez, M. F. M. Elias, N. A. Rahim, and N. Osman, "Current control techniques for three-phase grid interconnection of renewable power generation systems: A review," Solar Energy, vol. 135, pp. 29-42, Oct. 2016.

[14] S. A. Zulkifli, M. N. Hussin, and A. S. Saad, "MATLAB-Arduino as a low cost microcontroller for 3 phase inverter," in 2014 IEEE Student Conference on Research and Development, 2014, pp. 1-5.

[15] A. B. Rey-Boué, R. García-Valverde, F. D. A. Ruz-Vila, and J. M. Torrelo-Ponce, "An integrative approach to the design methodology for 3-phase power conditioners in Photovoltaic Grid-Connected systems" Energy Conversion and Management, vol. 56, pp. 80-95, 2012.

[16] L. Freris and D. Infield, Renewable Energy in Power Systems. John Wiley \& Sons, 2008.

[17] J. Chantana, Y. Horio, Y. Kawano, Y. Hishikawa, and T. Minemoto, "Spectral mismatch correction factor for precise outdoor performance evaluation and description of performance degradation of different-type photovoltaic modules," Solar Energy, vol. 181, p. 169-177, 2019.

[18] A. Satif, L. Hlou, M. Benbrahim, H. Erguig, and R. Elgouri, "Simulation and analysis of a pv system with p and o mppt algorithm using a pi controller for buck converter," ARPN journal of engineering and applied sciences, vol. 13, no. 9 , p. 9.

[19] O. O. Ogbomo, E. H. Amalu, N. N. Ekere, and P. O. Olagbegi, "A review of photovoltaic module technologies for increased performance in tropical climate," Renewable and Sustainable Energy Reviews, vol. 75, pp. 1225-1238, Aug. 2017.

[20] O. Dordevic, M. Jones, and E. Levi, "A Comparison of Carrier-Based and Space Vector PWM Techniques for Three-Level Five-Phase Voltage Source Inverters," IEEE Transactions on Industrial Informatics, vol. 9, no. 2, pp. 609-619, May 2013.

[21] R. Ekström and M. Leijon, "Lower order grid current harmonics for a voltage-source inverter connected to a distorted grid," Electric Power Systems Research, vol. 106, pp. 226-231, Jan. 2014.

[22] J. C. Hernández, M. J. Ortega, J. De la Cruz, and D. Vera, "Guidelines for the technical assessment of harmonic, flicker and unbalance emission limits for PV-distributed generation," Electric Power Systems Research, vol. 81, no. 7, pp. 1247-1257, Jul. 2011.

[23] P. Hwang, G. Jang, S. Moon, and S. Ahn, "Three-Phase Steady-State Models for a Distributed Generator Interfaced via a Current-Controlled Voltage-Source Converter," IEEE Transactions on Smart Grid, vol. 7, no. 3, pp. 1694-1702, May 2016.

[24] F. Ruz, A. Rey, J. M. Torrelo, A. Nieto, and F. J. Cánovas, "Real time test benchmark design for photovoltaic grid-connected control systems," Electric Power Systems Research, vol. 81, no. 4, pp. 907-914, Apr. 2011.

[25] A. Satif, L. Hlou, N. Hmina, and R. Elgouri, "Modeling and Simulation of a Photovoltaic System Connected to a Low-voltage Three-phase Utility Grid," IEOM conference Paris, p. 9, 2018.

[26] J. Chavarria, D. Biel, F. Guinjoan, C. Meza, and J. J. Negroni, "Energy-Balance Control of PV Cascaded Multilevel Grid-Connected Inverters Under Level-Shifted and Phase-Shifted PWMs," IEEE Transactions on Industrial Electronics, vol. 60, no. 1, pp. 98-111, Jan. 2013.

[27] “Arduino - Home.” [Online]. Available: https://www.arduino.cc/. 